\title{
Publisher Correction: Electrically driven three- dimensional solitary waves as director bullets in nematic liquid crystals
}

\author{
Bing-Xiang Li', Volodymyr Borshch', Rui-Lin Xiao', Sathyanarayana Paladugu', Taras Turiv (i) ${ }^{1}$, \\ Sergij V. Shiyanovskii ${ }^{1}$ \& Oleg D. Lavrentovich (1) ${ }^{1,2}$
}

Correction to: Nature Communications; https://doi.org/10.1038/s41467-018-05101-y; published online 25 July 2018

The original version of this Article contained an error in the description of Supplementary Movie 7, which incorrectly read 'Collision resulting in annihilation of two solitons. $U=45.1 \mathrm{~V}, f=600 \mathrm{~Hz}, T=50{ }^{\circ} \mathrm{C}, d=8.0 \mu \mathrm{m}$. The original movie is taken at the frame rate of $91 \mathrm{fps}$. The playback speed is $7 \mathrm{fps}$.' The correct version reads 'Death of a soliton at a dust particle. $U=65.6 \mathrm{~V}, f=800 \mathrm{~Hz}, T=50{ }^{\circ} \mathrm{C}$, $d=7.7 \mu \mathrm{m}$. The original movie is taken at the frame rate of $92 \mathrm{fps}$. The playback speed is 7 fps.' The HTML has been updated to include a corrected version of the 'Description of Additional Supplementary Files' file.

Published online: 30 August 2018

\begin{abstract}
(c) (i) Open Access This article is licensed under a Creative Commons Attribution 4.0 International License, which permits use, sharing, adaptation, distribution and reproduction in any medium or format, as long as you give appropriate credit to the original author(s) and the source, provide a link to the Creative Commons license, and indicate if changes were made. The images or other third party material in this article are included in the article's Creative Commons license, unless indicated otherwise in a credit line to the material. If material is not included in the article's Creative Commons license and your intended use is not permitted by statutory regulation or exceeds the permitted use, you will need to obtain permission directly from the copyright holder. To view a copy of this license, visit http://creativecommons.org/licenses/by/4.0/.
\end{abstract}

(C) The Author(s) 2018

\footnotetext{
${ }^{1}$ Liquid Crystal Institute and Chemical Physics Interdisciplinary Program, Kent State University, Kent, OH 44242, USA. ${ }^{2}$ Department of Physics, Kent State University, Kent, OH 44242, USA. Correspondence and requests for materials should be addressed to O.D.L. (email: olavrent@kent.edu)
} 